\title{
Phenomenology of Online Spaces: Interpreting Late Modern Spatialities
}

\author{
Viktor Berger ${ }^{1}$ (1) \\ Published online: 13 May 2020 \\ (c) The Author(s) 2020
}

\begin{abstract}
Sociological theories of space have so far not provided an in-depth analysis of online spaces. The paper addresses this issue by means of Löw's relational theory of space. As this theory mainly focuses on material spaces, it is necessary to embrace the phenomenological perspective in order to apply it to the virtual realm. More recent phenomenological research has highlighted the ongoing mediatization or virtualization of the life-world. These theories, and presence research more generally, are useful for examining the layers of virtual presence. This paper focuses on two emblematic types of spaces: multiplayer online role-playing games and Skype video chats. The first represents an online version of a Schutzian finite province of meaning, while Skyping is an example of how the paramount reality of everyday life expands into the virtual realm. Albeit differently, actors in both cases constitute hybrid, virtualmaterial spaces with various forms and degrees of virtual presence. User experiences in these spaces are in line with contemporary sociological diagnoses indicating the vanishing experience of living in space and the general tendency of late modernity to question previous social forms of modernity.
\end{abstract}

Keywords Space $\cdot$ Phenomenology $\cdot$ Mediatization $\cdot$ Late modernity $\cdot$ Virtual space $\cdot$ Theories of space $\cdot$ Alfred Schutz

\section{Sociology and (Online) Spaces}

Sociological theories of space have provided in-depth analyses of how material spaces are created, represented, perceived and lived by actors. Notably, this interest in spatiality is not only due to the recent spatial turn (Soja 1989). Classical theories had already scrutinized how social processes and actions project themselves into spatial relations and how the material forms that are created in this way affect

Viktor Berger

berger.viktor@pte.hu

1 Faculty of Humanities, Department of Sociology, University of Pécs, Ifjúság útja 6., Pécs 7624, Hungary 
social life (Simmel 1907/2009; Durkheim 1899/1982; Bourdieu 1996; Giddens 1985). In addition, questions concerning the perception, conception and classification of spaces emerged early on and continue to remain of importance (Durkheim and Mauss 1903/1963; Shields 1991). Besides the action theory approach (Löw 2001/2016), there is a great deal of diversity in theoretical orientations, including the (post)structuralist (Foucault 1982/1984), Marxist (Harvey 2001; Lefebvre 1974/1991) and actor-network theory accounts (Law 2002) of social spaces. A common trait among these theories is their focus on the constitution and perception of what they regard as "real" spaces.

Meanwhile, everyday life is increasingly influenced by modern information and communication technologies (ICT), chief among them internet-based tools and applications. We use the internet for work and personal reasons, and an ever greater share of our communication activities takes place via the internet. Since no medium is neutral, ICTs necessarily shape everyday life (Ollinaho 2018). Online spaces allow for a different kind of communication than face-to-face interactions, which affects both its style and content (Longhurst 2013; Friesen 2014). However, despite the importance of the online world for everyday life, theories of social spaces have so far not developed a deep interest in this social domain. This has to do with the fact that it is controversial whether online spaces are a subject of a theory of social spaces. In the following, I will argue that, indeed, sociological theories of space need to deal with online spaces. Online spaces, as understood here, are constituted when two or more people interact with each other using ICTs providing access to the internet. This is a purely formal definition - what matters is that the internet creates interactions between people who are not close to each other physically.

This paper will attempt to interpret two characteristic forms of online spaces. Without questioning the relevance of structural approaches, the paper will highlight the perspective of actors: how they create and perceive online spaces, and the relationship between online and physical space. In this, I will rely on the relational sociology of space as well as on phenomenological concepts of place and space (Löw, Waldenfels). While these theories offer useful points of reference, they also have significant shortcomings with regards to the online realm. The phenomenology of Alfred Schutz will therefore be deployed to overcome these theoretical problems. An updated Schutzian approach is a suitable complement to a relational theory of online spaces. Applying this theoretical framework, I will examine the spatiality of both video conversations and multiplayer online role-playing games. These spaces can be interpreted in the broader context of late modernity because they are typical forms of late modern spatial experience.

\section{Relational Theories of Space}

Sociological and social science approaches to space tend to be skeptical of absolutistic concepts of space, which conceive space as an immaterial container existing independently of the objects it comprises. In contrast, relational theories suggest that (social) spaces are constituted by their elements and the relationships between them, which are the products of human agency. According to 
Lefebvre (1974/1991), every society has a specific space, based on a dialectical, multi-element production process. Giddens (1985) interprets regionalization as a result of actions. According to Bourdieu (1996), physical space is relational because it mirrors the distinctions of relationally structured social space, while Simmel (1907/2009: chapter 9) examines the projection of social actions into spatial forms and the impact of these forms on social life. The phenomenology of Waldenfels (2009: 98f.) meanwhile envisages the human body simultaneously as a felt and lived entity and as an object in an arrangement of other objects. Acting subjects are aware of or sense this duality. Therefore, and because of the desires, fears and expectations that drive them elsewhere, actors never merge into the "here," meaning they are not only "here," but "there" as well, so that the visible is always undermined by the invisible. Consequently, space is not (only) rooted in objects, but also in the embodied subjects that constitute it.

Martina Löw's seminal work, The Sociology of Space. Materiality, Social Structures, and Action (Löw 2001/2016) is a prime example of a relational concept of space. According to Löw,

[S]pace is a relational arrangement of living beings and social goods. Space is constituted by two processes that must be analytically distinguished: spacing and the operation of synthesis. The latter makes it possible to unite ensembles of goods and people to one element. (Löw 2001/2016: 135)

The constitution of spaces by actors involves two elements. On the one hand, the organization of space (spacing), which refers to acts of positioning material (social) goods, people and non-human beings in relation to one another. As a result of spacing, a spatial order of living and inanimate objects is created, and the various configurations of bodies will build distinct spaces. Like Waldenfels, Löw also believes that actors do not only bring about spaces, but also act as elements thereof, since they not only put inanimate objects and non-human beings in relation to each other during the act of spacing, but also position their own bodies relative to those of others (Löw 2001/2016: 131). The second constitutive moment of space is the process by which the actor synthesizes the arranged bodies. Thoughts, memories, emotions and moods greatly influence how the subject constitutes a space. The same material arrangement will be synthesized quite differently by different (types of) actors (or by the same actor in different states of mind).

The question arises, however, whether the online world can be construed in terms of space. The notion of telepresence (Telepräsenz) in Waldenfels's concept refers to the fact that spatiality can be interpreted not only as "here" in the physical sense, but also as something that is transmitted by means of telecommunications (Waldenfels 2009: 108-111; see Friesen 2014). That being said, Waldenfels does not elaborate on his concept of telepresence in such detail that it could be applied without any further additions. Löw's concept of space is seemingly also open to the possibility of virtual spaces because it acknowledges the possibility of geographically non-continuous spaces constituted when remote objects are spaced and synthesized by means of telecommunications (Löw 2001/2016: 49, 75-86). But she has not herself provided an in-depth analysis of online spaces. 
There is good reason for this in Löw's theory. Except for the chapter on 'cyberspace,' spaces are understood exclusively as relational arrangements of material social goods (and living beings) "because these are the only ones that can be placed" (Löw 2001/2016: 188). In a recent article Löw and her co-author, Gunter Weidenhaus stress that

[A] sociology of space is appropriate for research when the 'where in the world' - the places at which the goods and living beings of space constitution are located

- is in fact relevant. It is only in this case that we are concerned with space rather than spatial metaphors. (Löw and Weidenhaus 2017: 655)

As an example of the difference between space and spatial metaphors, the authors refer to the internet which may be analyzed in terms of spatial metaphors, but the internet, for them, does not constitute spaces, because the 'where in the world' and the materiality of online platforms is mostly irrelevant (Löw and Weidenhaus 2017: 656). So "the internet is overall not a space, but rather a communication system that embeds spatial metaphors" (Löw and Weidenhaus 2017: 656). While this may be an accurate statement with regards to the internet from an outside point of view, the inner perspective of the actor proves to be a different case. If we aim to interpret how actors construct their spaces, we have to take a different approach than Löw (and Weidenhaus). An action theory or phenomenology of space should take the perspective of actors into account: assess how they construct, perceive, reconstruct, and modify their own spaces. In short, it has to show what space is for actors even if that leads to seemingly implausible results. Rob Shields draws an ontological distinction between the virtual and the concrete, the first being objects and states that are not tangible (e.g., memories), while the second refers to tangible and material things (Shields 2006). Both are perceived as real, and everyday experience is that of a mixed or augmented reality (Dubbelman 2013: 34; Löw and Weidenhaus 2017: 567, note 3). From a phenomenological point of view, something is real for actors if they have a coherent experience of it (Schutz and Luckmann 1973: 4), an idea applied here with respect to spatiality whether concrete or virtual.

If actors are in presence of objects and living beings to which they can take a position, which they can manipulate and which they synthesize through perception, feelings and thoughts, a space is constituted for them. In this respect, it does not matter whether these objects and living beings are concrete or virtual. This is the source of mixed or hybrid spaces for the actors. To treat virtual objects as possible elements of spaces may seem counterintuitive, but what matters in the case of mixed spaces is how actors construct their spaces. And for them, as shown in the two case studies, the virtual or online elements are part of their spaces. This marks a departure from Löw's account of spaces, it is therefore necessary to expand the concepts of co-presence, spacing and synthesis.

\section{The Phenomenology of Online "Others" and Online Presence}

The following chapter addresses the issues inherent to Alfred Schutz's concepts of consociates and contemporaries in a mediatized world focusing explicitly on how the phenomenology of others can be updated and on how ICTs create new forms of 
presence which are important to a sociology of online spaces. Schutz's work focused on the question of how social reality is constructed in a meaningful way. A key distinction is that between consociates and contemporaries. People connected by copresence are consociates because they are at the same place at the same time (here and now), and because they communicate "face-to-face," that is, they pay attention to each other. Under the circumstances of co-presence, such an abundance of signs is available for interpreting the other that it almost provides a sense of directness (Schutz 1932/1967: 167-172; Schutz and Luckmann 1973: 66). In contrast, contemporaries share only the same time, but are not physically present to each other (there and now). The category of contemporaries refers to people with whom we do not communicate presently, but about whom we have some knowledge. As their perception is necessarily indirect, actors frame contemporaries in terms of more or less anonymous categories and typically think of them as the representatives of functionary types. For instance, we have assumptions about how a physician or a firefighter behaves, what typical motivations drive them, but we do not envision them as individuals, rather as representatives of a social category. In contrast to the "we" relation among consociates that allows for at least some intimacy, the world of contemporaries is characterized by a more distanced "they" relation.

Schutz has been criticized for this simplistic dichotomy of consociates and contemporaries, and some scholars (Scriven 2015: 6.; Zhao 2004) believe that this distinction breaks down when it comes to interpreting mediated communications such as those taking place online. In this view, Schutz failed to engage thoroughly with forms of communications that do not require co-presence (such as the telephone) that existed at the time of writing. Undoubtedly, media-based communications were not a focal point in Schutz's work, but it nonetheless contains relevant remarks and observations. For example, he does not delineate a sharp boundary between consociates and contemporaries, and instead envisages transitions between these two poles. It is difficult to determine exactly when the we-orientation characteristic of consociates ceases and the they-relation of contemporaries begins. Schutz characterizes the writing of letters and telephone conversations as transitions, since some form of communication takes place in these cases, but-in contrast to the face-to-face interaction of consociates-without co-presence and its abundance of interpretable signs (Schutz 1932/1967: 177; Schutz and Luckmann 1973: 69). Schutz's strategy is to define these cases as transitional, intermediate forms, and then to discuss only the ideal types of consociates and contemporaries.

Contrary to Schutz's approach, more recent phenomenologically informed empirical studies do not consider these forms as intermediaries: instead of merely interpreting mediated communications as no longer a we-relation but not yet a they-relation (i.e., as in-between forms), they consider them a third category in its own right (Zhao 2004, 2005, 2015; see Scriven 2015). Communication modes that allow for the instant interaction of distant others are characterized by simultaneity and reciprocity. Zhao $(2005,2015)$ has introduced the concept of telecopresence to cases in which interlocutors share the same time but without physical co-presence. On the one hand, telecopresence corresponds to the they-relation of contemporaries, since the parties are not in physical proximity to each other. On the other hand, telecopresence is similar to the relationship among consociates, as actors use sensations in the 
now to make conclusions about the inner world of others. As technical mediation provides for an almost "direct" connection between the interacting parties, telecopresence represents a special kind of we-relation. While the face-to-face interactions of everyday life are characterized by an abundance of signs, telecopresence offers much fewer signals for interpretation: text, emojis, voice, images, etc.; thereby actors are obliged to assess the inner states of others based on a more limited set of signs.

The difference between the we-relation of consociates and the they-relation of contemporaries is not only a difference in grade, but one of quality. Telecopresence is a distinct phenomenon, giving rise to peculiar kinds of interaction rituals, styles and knowledge, in which much less consideration is given to the constraints of the body, as the subject is able to "multiply" itself in virtual spaces (Zhao 2005: $398-400)$. Zhao $(2004,2005,2015)$ proposes the introduction of a third category of consociated contemporaries to designate people with whom we interact online. Consociated contemporaries share time but not space with each other (there and now). Instead of (physical) co-presence, they are connected only by means of a medium, nowadays most commonly through the internet: instead of engaging in face-to-face interactions, they interact face-to-device, and while this relation can be considered a we-relation, it constitutes a mixture of intimacy and anonymity that is neither consociate nor contemporary in nature (Zhao 2004: 101f.). ${ }^{1}$

The latest phenomenological approaches have convincingly shown that it is possible to create presence with others even if they are not physically present. However, the concept of presence offers even greater possibilities: a more complex interpretation of telecopresence and of mediated spatiality. This can be achieved by turning to the literature on virtual environments, which combines the insights of computer science and the behavioral sciences. In this respect, Schultze's (2010) paper, which enumerates how (virtual) presence and its types are conceived in this field, is particularly informative.

According to Schultze, this literature perceives (virtual) presence as a psychological state in which experience is transmitted in whole or in part by technology, but wherein the virtuality of experience remains more or less unnoticed (Schultze 2010: 437). (Virtual) presence therefore is a much more layered phenomenon than phenomenological accounts would have us assume. Researchers of virtual presence use the term telepresence to denote cases when actors feel that they are in another, distant place (for example, the feeling of driving a car while using a simulator). Social presence refers to cases when actors feel that they are in connection with other distant people to whom they almost have direct access (telephone, video telephony, chat) (Schultze 2010: 437f.). At the intersection of telepresence and social presence, there is co-presence with the feeling that each actor has access to a remote subject

\footnotetext{
1 In their insightful paper, Hardesty and Sheredos (2019) take a different approach to update Schutz. They regard mediatized others as consociates if simultaneous communication is established. In their interpretation, physical immediacy is not a constitutive moment in experiencing others as consociates. However, this paper opted for the solution provided by Zhao because the abundance of interpretable signs in physical co-presence creates a difference to mediatized interaction and because of quality differences listed above.
} 
with whom (s)he is perceived to share the same (virtual) place. This is illustrated by multi-player online role-playing games. In this state, actors perceiving each other are able to manipulate objects in virtual space and to assume a position relative to one another (Schultze 2010: 438f.). Self-presence is the feeling that an individual's virtual representation fuses with the self, so that the self "settles in" a virtual body. First-person shooter video games are examples of this. Hyper presence refers to the impression of having a more authentic experience of oneself, of others, and of distant places in the virtual environment than in real life. For example, one might feel that (in contrast to the restrictive norms of the "real world") one can speak more freely with online acquaintances, thus creating more authentic relationships and self-knowledge. Finally, eternal presence is the impression that we are constantly among distant others due to the fact that we are connected to various communications platforms (Schultze 2010: 438f.). A user who works alone most of the time may have the feeling of not being alone, as (s)he is always "online" and communicates constantly. These clear cases of virtual presence often occur in combinations when using different devices and software. ${ }^{2}$

Self-experience is multi-layered both offline and online. Riva et al. (2004) distinguish between three levels of presence in both spheres. Proto presence refers to the basic but not conscious proprioceptive level at which individuals feel a bodily presence and consequently are able to distinguish themselves from the surrounding environment. The notion of a technologically mediated proto presence is relatively new, as this was not technically feasible for a long time. The second level is core presence, which refers to the subject's conscious sense of being present in the here and now. It involves processes of conscious filtering of sensory data, acts of attention allocation and reactions to these data. Finally, extended presence denotes the feeling of being present in a given environment as an autobiographical and historical subject with a relatively persistent identity. Presence is felt all the more intensely at this level, as subjects have the impression that events are relevant to their processes of identity creation. The various types of media produce presence at different levels. Textual media (books, web portals) may activate extended presence, and two-dimensional virtual representations (TV, computer games) may initiate the emergence of core presence, while proto presence can be realized through advanced virtual reality devices (Schultze 2010: 443f.). The three levels of self-presence do not necessarily coincide at equal intensity, neither in offline nor in online environments (in a given situation, a person can be highly present at one level, but may show lower presence at the other two levels). However, it is also possible for the three levels of self-presence to be aligned. In both the offline and the online sphere, a flow-like maximum presence can be achieved if a person is immersed in a situation, if (s)he focuses on all three levels on a specific activity and/or external environment (Riva et al. 2004: 415-417).

Despite overlaps between forms of co-presence and self-presence in terms of their content, these notions demonstrate the possibility of presence in online

\footnotetext{
2 The impact of presence research can be seen in Game Studies where similar forms of presence were identified. For instance, Nitsche (2008: 205) distinguished personal, social and environmental presence.
} 
environments. Offline, actors perform acts of spacing and synthesis, and thus constitute spaces under circumstances of physical co-presence in everyday life; as a result, a sense of "here" arises that enables subjects to experience their bodies as objects of an encompassing space. However, the concept of virtual presence-along with its different forms and levels_-suggests that spacing and synthesis, the very acts of constituting space, are not only possible in material spaces, but also in virtual environments. If actors have a sense of space while utilizing advanced means of communications, then a relational theory of space has to reconstruct the logic of how these online spaces are constituted.

\section{Mediatization of the Life-World and Finite (Online) Provinces of Meaning}

A phenomenology of the present cannot avoid clarifying the role that media play in the construction of the life-world. The following chapter recalls the theory of mediatization of the life-world and addresses the question whether the online realm is an extension of the paramount reality of everyday life or a reservoir of finite provinces of meaning. Couldry and Hepp (2017), in relation to the present, talk about the mediated construction of reality, which refers to four intertwined processes. On the one hand, this includes a growing emphasis on mediated communications and a relative loss of importance of face-to-face interactions. Secondly, by using technical devices (such as smartphones) on a day-to-day basis, people can easily incorporate past communications into current interactions. Thirdly, media and their contents, always being available to actors, represent important resources of everyday faceto-face interactions, as media provide us with more things to talk about (pictures, news, gossip, events on social media, chats with others, etc.). Fourthly, living in a mediatized environment shapes the values, habits, and norms of people (Couldry and Hepp 2017: 28f.). As a result, "[o]ur communication today in the here and now is thoroughly interwoven with various media" (Couldry and Hepp 2017: 29).

According to Ayaß, the structures of life-worlds have demanded mediality (for example, writing) since the dawn of the first civilizations, as it makes it possible to transcend the spatiotemporal constraints of the here and now and stabilizes social structures (Ayaß 2014: 94-96). Ayaß states, in agreement with Couldry and Hepp, that media are nowadays so ubiquitous that it is no exaggeration to speak of "media structures of the life-world" (Аyaß 2014: 95). The elements that are used by subjects to construct their stock of knowledge at hand (categorizations, schemas, typifications) increasingly come from media. For example, our knowledge about the functionary type of the physician is partly constructed by previous personal experiences, but to an increasing degree by what we saw in movies, TV series and what we have read in newspapers, novels, and so forth. Ollinaho goes even further, and according to his insightful study, the term mediatization is an insufficient conceptual tool for understanding the ongoing transformations of the life-world because infocommunication technologies not only mediate interactions but also create new (virtual) domains of social life (Ollinaho 2018: 195). 
There are two opposing schools of interpreting the online world. One of these, the virtualization thesis, conceives of this domain as an extension of the paramount reality of everyday life (Ollinaho 2018; Butnaru 2015), since using the internet does not suspend actors' default natural attitude and pragmatism, but only modifies it slightly. For instance, in emails and chats, rules of conversation and of impression management are not suspended but only modified to fit the new conditions of online interactions (abbreviations, slang terms, proper use of emojis and gifs, how to interpret if someone is not replying, and so on). According to the other view, at least some parts of the online realm (online game worlds, online gambling, forums of religious groups, and others) are to be interpreted, as Schutzian finite provinces of meaning (Scriven 2015; Ayaß 2017; Hardesty and Sheredos 2019; Steets 2019). Considering these approaches, the greater part of the online world has to be interpreted as an extension of the paramount reality (instant messaging, video telephony, social media, news portals, webshops, etc.), but there are also exceptions where finite provinces of meaning emerge.

According to Schutz, finite provinces of meaning are autonomous domains with a distinct style of experience and cognition that are different from the natural attitude of everyday reality (Schutz and Luckmann 1973: 22-34). The life-world-as the horizon of all meaningful experience-encompasses all finite provinces of meaning. The world of dreams and daydreams, theater, religious experiences, science, games, jokes, and poetry are all finite provinces of meaning. The world of everyday life (or seen from the perspective of the actor, the world of working) is also a province of meaning, but - as a prerequisite for all the others - it is the paramount reality, and actors always return to it. Nonetheless, other sub-universes have their own logic that cannot be traced back to everyday reality (or to the other provinces). In a certain passage of On Multiple Realities, Schutz describes the "leap" from one province to the other as a shock because it changes the subject's specific tension of consciousness, the attention to life (Schutz 1945/1962: 231). Although it is possible to enter finite provinces of meaning without media products, media, according to Ayaß, offer plenty of opportunities to access these provinces. After the leap to another sub-universe is performed, actors are physically still present in the paramount reality of everyday life, but experience little of their surroundings (Ayaß 2014: 103), albeit with varying degrees of immersion (while reading a novel, one can be immersed to a higher or a lesser degree in the fictional world).

To engage thoroughly with forms of online presence, it is necessary to recount how Schutz defines finite provinces of meaning. According to Schutz (1945/1962: 230f.), finite provinces of meaning differ along six criteria. Using the example of massively multiplayer online role-playing games (MMORPGs), these six aspects can serve to demonstrate that the online realm is not only an extension of the paramount reality, but there may be finite provinces of meaning in the online world.

(1) Each province is characterized by a specific tension of consciousness. In the world of everyday life, consciousness is characterized by wide-awakeness and the "highest tension originating in an attitude of full attention to life and its requirements" (Schutz 1945/1962: 213). Actors use their knowledge (typifications of others or "how to" recipes") in a pragmatic way to accomplish their 
goals. MMORPGs are also characterized by wide-awakeness, and a state of "highest tension" is also possible, but in this case, the attention is not focused on life and its requirements, but on a game world with a different logic. The motivation behind focusing attention to various activities in the games is actors' desire to make progress in the game world (Dubbelman 2013: 101).

(2) Provinces of meaning have a specific epoché, a special kind of suspension of doubt. The way doubt is suspended differs across various provinces of meaning. In everyday reality we suspend the doubt in our knowledge about society. For example, most of the time, we do not question our knowledge about functionary types (how they act, what motives drive them, etc.), we suspend our doubts in the accuracy of our knowledge in order to be able to act. A key difference between the paramount reality and online game worlds emerges, because in game worlds constraints of everyday life do not prevail (Ollinaho 2018: 203). The specific kind of knowledge is different in online gaming worlds, as it takes other types of objects (or characters, beings) and other regularities of action for granted than is the case in the world of everyday life. To accomplish the overarching goal of improvement, actors do not suspend their knowledge of the game world.

(3) Provinces have a prevalent form of spontaneity. In the world of daily life, actors set goals and try to accomplish them through bodily movements (Schutz 1945/1962: 230). This pragmatic attitude is created by the fundamental anxiety that "I know that I shall die and I fear to die" (Schutz 1945/1962: 228). In the world of MMORPGs, actors also pursue targets, but they are not motivated by fundamental anxiety, either because death is not possible in the game or because it is not permanent. There is, however, a different form of fear, namely the fear of a threatening object in a reasonable range (Möring 2019), but since permanent death is not possible, these games have a different structure of relevance based on the anxiety of not making progress.

(4) Each province of meaning involves a specific self-experience. As Ollinaho writes, "[w]hile the form of experiencing one's self in the working self is the total self, in virtual worlds such self acts typically through an avatar of some sort" (2018: 202). The intensity of virtual presence may vary across different types of games (Hardesty 2016), but in general, self-experience in game worlds differs from that in paramount reality, as this experience is created by actions, qualities and abilities that are often impossible in physical reality.

(5) Provinces have a specific mode of sociality. The sociality of the paramount reality is "the common intersubjective world of communication and social action" (Schutz 1945/1962: 230). For Game Studies, it is a fundamental issue whether games represent sub-universes separated from the rest of society, or if they can be interpreted as extensions of the social world. According to representatives of the latter point of view, players bring their values, norms and specific principles of organizing relations (e.g., hierarchies) to the games, so that these cannot be considered as worlds independent of society (Pargman 2008). However, Games Studies scholars mostly believe that games represent a "magic circle" which temporarily suspends the relevances of everyday life (Hardesty and Sheredos 2019: 348f.). Furthermore, intersubjectivity is not enough to qualify a domain as not being a finite province of meaning; religion, for example, is a finite prov- 
ince of meaning marked by intersubjectivity (Ayaß 2017: 529), and MMORPGs can therefore also be considered autonomous provinces if other criteria are met. In addition, the sociality of MMORPGs is characterized by a special stock of knowledge and by distinct personal and functionary typifications of others, which clearly differ from those of the paramount reality (Scriven 2015).

(6) Finite provinces of meaning are characterized by a specific temporality. The time perspective of paramount reality is twofold: on the one hand, it encompasses the universal cosmic time given to everyone (clock-time), and on the other the lived time (durée) experienced by the actor alone (Schutz 1945/1962: 230f.). Although in the worlds of MMORPGs the durée of the actor remains, these sub-universes detach from the universal cosmic time of the world of everyday life and usually create their own common temporality.

An additional argument against finite provinces of meaning in the online context is the absence of a sense of shock when we access the online world, which, according to Butnaru (2015: 76) indicates that actors do not leave the paramount reality. However, following Ayaß, it should be pointed out that although Schutz himself used the word "shock" in On Multiple Realities to characterize the leap, he did so rarely. He more often wrote about the temporary, gradual, less shocking nature of these transitions: small shifts that actors make, even in a matter of seconds (Ayaß 2017: 530). Nor does it deny the existence of finite provinces of meaning if, in the sense of presence research, maximum presence is not achieved in online worlds, given that maximum presence is also rare in everyday reality. Another argument against finite online provinces of meaning is that the online world has an impact on the paramount reality and its routines, which also suggests that the online world is part of the paramount reality. However, this is also not a decisive argument, since even "traditional" finite provinces of meaning such as religion, art, dreams or fantasies have an impact on everyday life (Ayaß 2017: 530). Furthermore, provinces of meaning are not necessarily individual experiences, they might be social in nature as exemplified in science, religion or art. To sum up, in light of the fact that MMORPGs have a different accent of reality, and given that players can immerse themselves in this fantasy world, they can justifiably be classified as finite provinces of meaning (see also Ayaß 2017: 529; Steets 2019: 90f.).

\section{Spaces of Online Role-Playing Games and Video Telephony}

The discussion of phenomenological approaches of the online world argued that the online realm is to a greater part an extension of everyday life, but it is also a reservoir for online provinces of meaning (illustrated by the case of MMORPGs). This section reconstructs the constitution of hybrid, virtual-material spaces from the perspective of actors. These mixed or linked spaces combine material with virtual objects through (virtual) spacings and synthesizing. The virtual elements of users' hybrid spaces may be provided by a finite province of meaning or represent the extension of everyday life. The first is exemplified by the case of MMORPGs and 
the second by video telephony. The spaces constituted by actors in these settings will be interpreted on the basis of two examples (World of Warcraft and Skype).

MMORPGs have distinct features that set them apart from other online worlds. Life simulation games like Second Life and The Sims, although they also provide a possibility for immersion and presence (Houliez and Gamble 2013), can be considered to be extensions of everyday life. In contrast, MMORPGs constitute finite (online) provinces of meaning. In general, games represent finite provinces of meaning, however, there are significant differences among various types and playing modes of them. There are single-player games which can only be played by one person, and there are also single-player modes of otherwise multiplayer games. In these instances, users play against enemies in the game environment (Player versus Environment, PvE), and there is no human interaction. First-person shooters (FPSs) like Doom or Call of Duty focus on weapon centered combats from first-person perspective, whereby the player perceives the action through the eyes of the player character. FPSs are often played in single-player mode, but they also make multiplayer and recently massively multiplayer modes possible. The key difference to MMORPGs is that in FPSs, because of the first-person perspective, the bodily felt proto presence is achieved more easily than in MMORPGs and that FPSs emphasize player skill more than player statistics (evolving through stepping up to higher levels). In contrast to single-player games, single-playing modes, and other forms of PvEs where humans interact with non-human agents, MMORPGs foster the creation of coalitions (for example, guilds) with internal social norms, hierarchies and meaningful "tribal" identities.

The fantasy realm of World of Warcraft (WoW), an example of MMORPGs, has its own mythology, specific types of beings and characters, a social hierarchy and a system of norms and values created by the players. Its logic and accent of reality differ from that of everyday reality: the relevance structure of the actors is different from the pragmatism of the natural attitude of everyday life, since alternative recipes of action, schemas and typifications have been formed in WoW. Thus, based on Schutz's terminology, WoW is a finite province of meaning: a self-referential, meaningful, yet social world into which actors can leap through a shift. They suspend the pragmatic attitude of everyday life to align with the reality accent of the game.

Players typically see each other's avatars, but are aware that they are controlled by players similar to them. They know that their in-game set of relevances differs depending on who is who and where they stand in the game, but they also unconsciously assume that if they swapped "places" with each other, they would see the game world and its elements and events just as the other does. ${ }^{3}$ As such, players interacting with each other are consociated contemporaries. In contrast to the abundance of information of physical co-presence, each player has to draw conclusions about the inner consciousness of others using a limited set of perceptions: playerdriven actions, programmed emotional reactions and the static movements of their avatar, as well as textual and voice-based communications (Scriven 2015: 11).

\footnotetext{
3 This is a transformation of the general thesis of the reciprocity of perspectives (Schutz and Luckmann 1973: 60), applied to the online game world.
} 
However, this relationship is simultaneous and reciprocal, and therefore it is not one between mere contemporaries.

Scriven (2015) provides an excellent phenomenology of WoW, pointing out that players construct typifications specific to the objective meaning context of the game world (Zhao 2015: 111). On the one hand, they construct functionary types - that is, typified categories of actors with typical motives, objectives and behaviors within WoW (e.g., "noob," "loot ninja" or "griefer"4). On the other hand, they also create personal ideal types of each other, and by doing so, they consider others not as representatives of a category, but as unique and individual persons (although simplifications are inevitable). Compared to the personal types of everyday life, those in an online role-playing context are based on less information, which typically refers only to this particular context (Scriven 2015: 13f.).

MMORPGs in the vein of WoW make it possible for the various forms of virtual presence to arise, meaning that participants may feel actually present in this world, oblivious to the fact that this is a technically generated experience. Telepresence emerges if actors feel that they are present at a remote virtual location (for example on a battlefield), social presence if they perceive each other, and (virtual) co-presence if they coordinate actions while perceiving the other as being present in the same virtual space. If players strongly identify with their avatar, self-presence is created. Playing WoW and similar games facilitates self-experience at various levels and degrees: core presence, given the need for the selective and conscious allocation of attention in the game; extended presence, if acts and events in the game are interpreted within a narrative framework that is important for the player's identity (for the possibility of avatars to affect self-identification in online worlds see Taylor 2002: 51-55). During an intense gaming experience, the actors' extended and core presence reach a high level focusing largely on the world displayed on the screen. This intensive experience may also lead to the rise of proto presence. Several approaches in Game Studies point out that to players, the devices they use for the game-be it a joystick, a controller or else-do not appear to be objects but as extensions of their bodies which extend into virtual space (Bayliss 2010: 51; Crick 2011; Klevjer 2012; Chin 2017; Di Letizia n.y.). ${ }^{5}$ This perspective draws on Merleau-Ponty's interpretation of tools as prosthetic extensions of the body (Merleau-Ponty 1945/2012: 176, 260f.). Players perceive their avatars' on-screen movements and actions as their own. The players are thus hybrid actors in the sense of Latour (1991/1993).

Players in multiplayer online role-playing sub-universes find themselves among consociated contemporaries and together constitute their specific spaces. The players perform acts of spacing in the physical space. They sit down on a couch or in an armchair, and move their hand and fingers on the mouse and keyboard. The technical equipment consists of multiple elements: gamer desk, PC or notebook, screen(s), gaming chair, headset, and so on. Previously, they have decided which material

\footnotetext{
${ }^{4}$ Noob: newbie, beginner. Loot ninja: A player who unrightfully takes the prey (loot) from his teammates. Griefer: a player who ruins the gaming experience of others. (Source: https://wowwiki.wikia.com/ wiki/Loot_ninja; https://wowwiki.wikia.com/wiki/Griefer).

5 See also the blog entry by Gattlet: https://www.firstpersonscholar.com/virtual-bodies-in-virtual-world $\mathrm{s} /$.
} 
objects they want to be part of their physical gaming space (buying equipment, preferring one brand over another, building high-performance gaming setups). Choices made in this way are meaningful to individual players as well as to their communities (for example, a good setup is a source of prestige). Material objects arranged in a meaningful way constitute the space of the gaming room. Typical ways of arranging objects are: making it resemble to a cockpit, using multiple screens and accentuating a technology dominated atmosphere by adding colored led lights, special gaming speakers and $\mathrm{WiFi}$ routers or other accessories to the arrangement.

Besides of spacings in the physical world, actors also position themselves virtually in the online world: they have to choose a playing mode PvE or PvP (person vs. person) and also their perspective (the more common third-person view, or the recently added possibility of one-person perspective). By moving, acting and communicating in the virtual world, they establish structured relations and create spaces that consist of virtual objects and creatures as well as their consociated contemporaries. Players are to a certain degree able to customize the position of the camera by zooming in and out and by setting the angle They might also visit "Cross Realm Zones" (CRZs) which refer to places where players can see players from other realms who are in the same over-all gameworld but on a different server or realm and are therefore usually not visible to them. Hardest and Sheredos (2019: 362) call the CRZs a source of trans-ludic experiences.

Actors synthesize a single hybrid space, in which the virtual space (constituted under circumstances of virtual presence in the game's finite province of meaning) and the space of the body and its physical surroundings are linked to each other. With regards to the synthesis of the virtual part of this hybrid space, it is important to note that game spaces are not allegories of physical spaces rather representational or lived spaces in a Lefebvrian sense (see Günzel 2019a, b). The special type of space (or spatial concept) a game expresses and enacts has an effect on how it is lived by the players. In WoW, the third-person view is the most common perspective, but first-person mode is also possible. According to Möring (2019) both are synthesized as "play spaces" which refer to a space perceived as the in-between range between a threatening object and a threatened player. Although stronger accentuated in the first-person mode, both the first-person and the third-person perspectives are exemplifications of directed space to which a difference of front and back is crucial: while the front refers to a dangerous region (the enemy is there), the back is a safe space, a shelter (Günzel 2019a: 30f.). The first-person mode represents the spatial concept of intentional spaces (Günzel 2019a: 32-34), because the game space is distorted according to the directedness towards relevant objects. Although to a lesser degree, the third-person view may also be considered as an exemplification of an intentional space, since material objects and buildings are arranged in a way so as to "provide orientation in the game, and to allow to act according to its rules" (Steets 2019: 93). ${ }^{6}$ The specificity of the third-person view is "the mix of a first person experience with a following camera" located typically on the avatar's

\footnotetext{
${ }^{6}$ In both modes, threatening beings may have a semicircle drawn around them which represents the zone from which these object are reachable by the avatar's weapon (for example, a sword).
} 
shoulders or above it (Günzel 2019a: 35). As a way of synthesizing space, it refers to a "schizoid" state where the avatar is not seen purely from a third person view (as a completely different body), but from a camera angle which is attached to the body of the avatar. To sum up, with slight differences, first-person and third person views of the gaming experience in WoW allow the virtual space of the game to be synthesized as intentional and directed "play spaces". The degree of immersion into this virtual component of players' 'linked' hybrid (virtual-material) space can vary, but material reality does not completely disappear for them. In the case of a strong virtual presence, the virtual aspects of the hybrid 'linked' space dominate, so much so that game spaces may also affect how we perceive physical settings, for instance, our living room (Nitsche 2019).

While, according to Schutz, games in physical settings also constitute finite provinces of meaning, MMORPGs (and among them WoW) have unique features which set them apart from "offline" games: players perceive each other as avatars, not as embodied persons but as consociated contemporaries; typifications are based on a limited set of perceptions referring only to the context of the online game; the various forms of virtual presence made possible by the game; the interconnectedness of spacings in the physical world and virtual spacings; the hybridity of synthesized spaces. Players feel various forms of virtual presence in the online realm and others appear to them as disembodied beings (apart from their avatars), therefore the set of signs perceived by players is limited to the context of the game. This is in stark contrast to games in physical settings where players perceive each other as consociates and perception is rife with information not related to the game (looks, expressions, attire, smells, etc.). In this sense, MMORPGs provide the pure game experience, because it is based on perceptions related solely to the game itself.

In contrast to MMORPGs, in video chat applications such as Skype, actors do not leap into a mediatized finite province of meaning, but, in line with Ollinaho's (2018) virtualization thesis, remain grounded in the extended paramount reality. Although the remote other displayed on the screen may pose a challenge in this regard, subjects do not suspend their natural attitude, but only alter it moderately. The parties involved are also consociated contemporaries towards each other. Compared to MMORPGs, such applications allow us to learn more about our mediated contemporaries, as we hear what they say and how, see their faces as they speak, and can often perceive their gestures and environments. Another difference stems from the fact that in the world of multiplayer online role-playing games, people who were previously unknown to each other establish relationships that revolve around the online world, while Skype is typically used for communication among people who already know each other.

The impression of (virtual) presence depends on to what degree actors become oblivious to the technical mediation of their communication and come to perceive the person on the screen as "truly" present. Qualitative research on Skype (Aguila 2011; Friesen 2014; Longhurst 2013) has produced ambivalent results. Although in many cases the impression of "being together" came about, technical difficulties, visual distortions, distractions of attention or aversion to the software acted to counter any sense of virtual presence. Furthermore, many participants who experienced a high-level of virtual co-presence stated that a latent feeling of separation remained 
(Aguila 2011: 308f.). However, as noted by both Ayaß (2017) and Schultze (2010), (virtual) presence is not divalent (existing/not existing), and should instead be interpreted as a continuous scale, given that presence can take place at a lower or a higher level.

Considering the various types of virtual presence, the concept of telepresence is less relevant for Skype and similar applications, due to the fact that actors do not have the impression of being at a remote place, but experience an expansion of their own space. They typically feel that the space of the room they inhabit is extended by that of the remote partner with whom they interact (Aguila 2011: 307). ${ }^{7}$ Social presence, on the other hand, does apply to video chats, as it is possible for the impression that the other is present to evolve. Nevertheless, virtual co-presence (the feeling that the other is present at a distant location and being there with others) only emerges partly. Although actors communicating through Skype may have the illusion of sharing a common space, this space neither feels distant nor is it the same for all interacting parties. If my material space is extended through Skype by a virtual component of your space, its make-up is exactly the opposite from your point of view (your material space is supplemented by my space, which you perceive only virtually). Self-presence is not possible in this case, as actors do not possess a virtual representation or avatar in a virtual setting, so they cannot have the feeling of inhabiting such a virtual body. Hyper-presence is also less applicable to Skype-type communications, since the participants - by using voice and image transmissions-do not really detach from the roles and norms of everyday life and the impression of a "more real" self and "more authentic" relations cannot evolve. Video conversations usually last for a limited period of time and do not create an eternal presence on their own, however, it is possible for eternal presence to arise through the combination of video chat with other forms of interactions (text-based chat, social media, email, SMS, phone).

Of the three levels of self-experience, extended presence is the most likely to occur, since engaging with family members, colleagues and acquaintances can produce the feeling of being woven into biographical narratives. Core presence is also possible, provided that actors allocate their attention to the here and now of the interaction. However, proto presence is presumably less evident in video chats, given that actors are not present through a representation in a virtual world, which prevents the emergence of any unconscious and embodied feeling of virtual presence.

To summarize, in the case of video chats, not all kinds of virtual presences and not at all levels of virtual self-experience exist, but the online presence that does arise provides a specific spatial experience to the participants. Research involving users of Skype and similar services shows that special acts of spacing take place. How the camera-equipped computer or mobile phone is placed is important, as it determines what kind of image is transmitted to the other. For example, Longhurst

\footnotetext{
7 Aguila described the experiences of users as follows: "On Skype, we may feel like we share the same space despite the distance. We may feel so at home that we, in fact, expand our home to include the Skyped-in other. (...) Now, home feels like my bedroom plus your living room; your living room plus my kitchen. My physical space seems to include you virtually when we Skype” (Aguila 2011: 307).
} 
(2013: 671) remarks that her interviewees usually placed their notebooks in the center of their living room. By positioning the camera, users make certain bodies and objects visible, while other things remain hidden, intentionally or not. Using a mobile phone does not eliminate the issue, it only allows for greater movement. The position of the user's face and body in relation to the camera (proximity, central or peripheral position, angle, etc.) is also relevant because it can influence the course of the interaction and the emotional state of the participants.

Users' descriptions reveal that the synthesis of space once again happens by linking a virtual and a material space. According to Longhurst, many users she interviewed who live far from their family members felt that the latter become part of their space through video telephony. Those who disliked video chatting felt that way only because they had the sensation of others entering their private space (Longhurst 2013: 673-675). Either way, space is complemented by a virtual segment, although in this case the actors' hybrid linked space is not comprised of the paramount reality and the space of a finite province of meaning, but of two distant segments of the world of everyday life, a physically present and a virtually represented one. Contrary to the typical space experience of multiplayer online role-players, the dominance of the virtual space is not clear cut and the two components are almost equal, largely due to the fact that proto presence is usually not achieved through Skype, as the experience retains its connection to the material environment of the body.

During video chat sessions, actors thus synthesize their space by attaching or linking a virtual space to their material one. This is a formal description of this type of synthesis, through the emotional atmosphere it generates for actors may vary in line with their individual situation and emotional state. For example, when family members Skype with each other, they typically create a real-virtual hybrid space that is saturated with positive emotions into which they happily sink (Longhurst 2013: 669-673). Conversely, during a work-related video conference, a more formal tone prevails, causing participants to exercise greater control over their behavior because they feel the objectifying gaze of others (Friesen 2014: 23f.).

The specific moods or atmospheres of family conversations or work-related video conversations (to which users are attuned) are similar to situations in physical settings (family conversations tend to be more intimate and emotion-based, while work situations engender formal communications), but there are crucial differences which create the special experience of mediatized communication and the peculiarity of space synthesis. Communicative availability in face-to-face situations is not divalent: it constitutes a scale between the two opposite poles (availability or unavailability). ${ }^{8}$ Conversely, in video conferences one is either available or not (being part of the conversation or not) losing many subtleties of "offline" availability. Other subtleties of face-to-face encounters also disappear in work-related video conferences. Take for example a business meeting in the physical world: employees have to move through transitional spaces like hallways, stairways, elevators, these bodily

\footnotetext{
${ }^{8}$ An example of an in-between availability may be the case where people are physically present in a larger office space (possibly far from each other), and they have a sense of others being also present there but momentarily they do not engage in focused interaction with each other.
} 
movements create opportunities for spontaneous, non-straightforward, informal, and improvised interactions with others as the "water cooler chatter". Transitional spaces and their possibilities tend to be missing from mediatized video conferences, and the formal aspects dominate to a higher degree than in the physical world (Friesen 2014: 21f.). As Friesen put it, "It is as if their design [that of video conferences] is based on the narrow formalized definition of a meeting as structured precisely by agendas, minutes, rules and orders" (Friesen 2014: 22).

Another idiosyncrasy of space synthesis, both for work-related and personal video conversations, is the higher degree of (self)objectification and more possibilities for manipulative and deceptive communication. The objectifying gaze also exists in physical settings, but it is amplified in video conversations in a twofold way: users may objectify others because simultaneous and reciprocal eye contact is not possible, ${ }^{9}$ so it goes unnoticed if one stares constantly at the other (an action considered rude in "offline" interactions). On the other hand, because users also see themselves, they tend to objectify themselves and give great importance to how they look, how their facial expressions may seem to others. This creates enhanced opportunities to control our expressions given and given off (Goffman), which, in turn, enhances possibilities of manipulative and deceptive communication. The impossibility of simultaneous and reciprocal eye contact may make it harder for family video conversations to create positive emotional spaces. Skyped family conversations, moreover, operate with reduced cues (no olfactory or haptic perceptions, reduced audiovisual signs). The reduced set of significant cues and the lack of simultaneous and reciprocal eye contact is probably the reason why many users, while feeling "at home" in Skyped-in mixed spaces, also express feelings of lacking something. The happiness of being able to talk to a loved one goes hand in hand with an unfulfilled desire to the other.

In contrast to techno-optimistic visions, virtual presence remains different from offline co-presence, since media are unable to transmit what is in essence untransmittable (Waldenfels 2009: 110). As Waldenfels (2009: 110) states, since the visible is always undermined by the invisible in everyday communications, and vision is always stimulated by desire, there will always be additional elements to perceiving and constituting spaces that do not result from what is actually being seen or heard. Furthermore, the everyday experience of corporeality and spatiality is always made up of more than mere vision and hearing (e.g., sensations of smell or touch) which, again, cannot be transmitted. No medium can transmit these incommunicable aspects.

\footnotetext{
${ }^{9}$ On the impossibility of simultaneous and reciprocal eye contact see Friesen: „you cannot truly look an interlocutor in the eye since seeing another's eyes means looking at the screen. You can give the appearance of making eye-contact, but this actually requires looking away from the other, and into the camera" (2014: 25).
} 


\section{Conclusions}

Theories of late modernity emphasize three aspects: first, the relation between modernity and late modernity is that of continuity and change; second, social forms are getting more contingent or fluid than before; and third, late modernity is an era characterized by the integration and radicalization of contradictory tendencies. It is debatable whether the interpretation of spatialities is central or even relevant to theories of late modernity. Some scholars stress that new ICTs and advanced transportation technologies cause deterritorialization (Appadurai 1990), time-space compression (Harvey 1989), and the gradual replacement of "great expanses" through "great speeds" (Virilio 1998/2005: 123), which, according to them, result in the decreasing importance of spatial relations. However, theorists of spaces have pointed out that since every social relation is embedded in spatiality, spatial relations continue to be of chief importance for societies. According to this view, theorists and researchers of space have to investigate the changing ways (material and virtual) spaces affect our lives in order to add significant new layers to the diagnosis of late modern societies. In the following, I will argue that the interpretation of hybrid spaces may contribute to this endeavor with respect to all three aspects of late modernity.

Theorists of late modernity interpret the present in light of both historical continuity and change (Bauman 2000; Beck 1994; Giddens 1994). The duality of continuity and change is reflected in how actors typically synthesize spaces. According to Löw, actors up to about the 1960s typically perceived space as a continuous extension of concentric circles (on children: Löw 2001/2016: 65, on adults: Mayol 1994/1998). Löw aptly describes this urban spatial experience as that of living in space (Löw 2001/2016: 67). With the transition to late modernity the dominance of the experience of living in space has faded away. From the 1960s and 1970s onwards, the importance of neighborhoods as meaningful spatial-social units has waned in the metropolitan areas. The experience of living in space is complemented (but not substituted) by another: insularized socialization (Löw 2001/2016: 65-72). According to recent studies, today's metropolitan children or even adults do not experience space as continuous or as a gradually expanding concentric circle: space for them is discontinuous and made up of "islands" that are separated by empty spaces but connected by regularly used routes (Löw 2001/2016: 65-72; Vertesi 2008). It may therefore be appropriate to interpret these processes as indications of a general tendency towards perceiving space as more fragmented and insularized.

These novel ways of constituting space in late modernity are not entirely new, since the experience of living in space had already been questioned much earlier by the developing means of rapid transport (on the impact of trains: Schivelbusch 1977/1986). The fragmented perception of spaces in late modernity amplifies these tendencies. Moreover, in late modernity, ICTs allow the emergence of virtual presence or telepresence and of hybrid, "linked" spaces with material and virtual components that further interfere with the experience of living in space. The use of infocommunication devices conveys the experience of a multiplication, 
hybridization, fragmentation and multi-layering of spaces-complementing and intensifying the experience of urban, insularized spatiality. The spread of linked, hybrid spaces and the decreasing importance of living in space are consistent with two ideas advanced by Giddens: first, the notion that in late modernity there is a tendency towards experiencing sociality in an ever more indirect and mediated manner, and secondly, the idea that places are no longer thought of as parts of a larger unit, but rather as decoupled from overarching spaces (Giddens 1991: 17-21). Online spaces and states of virtual presence further radicalize this process of decoupling.

All this is in line with the second aspect highlighted by theorists. Late (or liquid) modernity is an era marked by uncertainty and contingency. The notion of liquid modernity (Bauman 2000) refers to the uncertainty and fluidity of social forms such as work, private life, identity or political orientation as a consequence of the ongoing sprawl of modernization processes. Alfred Schutz described the constitution of lifeworld as an intersubjective process between consociates and as an inquiry into the nature of contemporaries. The deep mediatization of the life-world in late modernity has blurred the difference between consociates and contemporaries, and as a result, the more fluid category of consociated contemporaries emerged. Consociated contemporaries have an increasing effect on how we act, think, feel and how we identify ourselves. The mediatization of everyday life and the spread of the internet changed the perception of reality marked by the growing importance of the virtual. The realness of objects and living beings is less and less a question of yes or no but more of graduality: consociated contemporaries are felt real (we sense their presence in our hybrid, virtual-material spaces) but their contours are, due to the reduced set of interpretable cues, less sharp than those of persons we have face-to-face interaction with. The mediatized other is surely here with us through chat, email, telephone, social media interactions or video conversation, but the lack of corporeality makes them less tangible. Interactions between consociated contemporaries are more saturated with uncertainty and the interpretation of the other is less firmly grounded (Seiler and Kidwell 2016).

A third characteristic of late modernity and modernity in general is the incorporation of contradictory tendencies. For example, modernity is said to be dominated by rationality (Weber 1904-1905/2010), while at the same time this era gave birth to the cult of romantic love (Giddens 1992) and hedonistic consumption (Campbell 1987). Late modern societies are essentially post-traditional, but there are strong fundamentalist counter-movements aiming to reclaim "ontological security" (Giddens 1994). Similarly, in late modernity, processes of economic, political, and cultural globalization trigger processes of deterritorialization (Guéhenno 1993/1995), which, in turn, provoke/initiate opposite tendencies of reterritorialization as evidenced by wars, geopolitics or reactions of states to close their borders in face of migration and pandemic crises. The constant exposure of people to online spaces may engender that physical spaces and borders formerly thought of as stable and firm are now perceived more contingent (Ahrens 2003: 175). On the other hand, this contingency also leads to the desire to establish meaningful attachments to physical places and spaces and to socialize face-to-face with each other. Being constantly available online (eternal presence) is often felt to be a source of stress and strategies 
of resistance arise (for example by employees not answering phone calls, replying delayed to emails). Clearly, there are limits to the mediatization of everyday life. To a certain degree, we need the physical co-presence of others without whom socialization, meaningful social identities and relations would not be possible. Humans are characterized by a compulsion to proximity (Boden and Molotch 1994).

Late modernity is marked by the radicalization of its inherent contradictions. With regard to space, late modernity amplifies modernity's tendency towards overcoming distances and rendering space less tangible, while on the other hand, these processes also create the need for spaces and places of identification. The proliferation of hybrid, virtual-material spaces, far from being the only contributing factor, is an important element of these parallel processes as it accelerates the contingency of the perception of spaces. Whether these late modern ambivalences and the mediatization of everyday life facilitate an "authentic existence" (marked by improved self-knowledge and interpersonal relationships) or, on the contrary, reinforce inauthenticity (Cass 1998) is one of the fundamental dilemmas of the mediatization of everyday life.

Acknowledgements Open access funding provided by University of Pécs (PTE). The author would like to express his gratitude to Katalin Füzér, Dániel Havrancsik, and the two anonymous reviewers.

Funding The research was financed by the Higher Education Institutional Excellence Programme of the Ministry for Innovation and Technology in Hungary, within the framework of the 4th thematic programme „Enhancing the Role of Domestic Companies in the Reindustrialization of Hungary” of the University of Pécs.

Open Access This article is licensed under a Creative Commons Attribution 4.0 International License, which permits use, sharing, adaptation, distribution and reproduction in any medium or format, as long as you give appropriate credit to the original author(s) and the source, provide a link to the Creative Commons licence, and indicate if changes were made. The images or other third party material in this article are included in the article's Creative Commons licence, unless indicated otherwise in a credit line to the material. If material is not included in the article's Creative Commons licence and your intended use is not permitted by statutory regulation or exceeds the permitted use, you will need to obtain permission directly from the copyright holder. To view a copy of this licence, visit http://creativecommons.org/licen ses/by/4.0/.

\section{References}

Aguila, A. (2011). Time and space on Skype: Families experience togetherness while apart. Explorations in Media Ecology, 10(3-4), 303-312.

Ahrens, D. (2003). Die Ausbildung hybrider Raumstrukturen am Beispiel technosozialer Zusatzräume. In C. Funken \& M. Löw (Eds.), Raum - Zeit - Medialität. Interdisziplinäre Studien zu neuen Kommunikationstechnologien (pp. 173-190). Wiesbaden: Springer.

Appadurai, A. (1990). Disjuncture and difference in the global cultural economy. Theory, Culture \& Society, 7(2-3), 295-310.

Ayaß, R. (2014). Media structures of the life-world. In M. Staudigl \& G. Berguno (Eds.), Schutzian phenomenology and hermeneutic traditions (pp. 93-110). Dordrecht: Springer.

Ayaß, R. (2017). Life-world, sub-worlds, after-worlds: The various 'realness' of multiple realities. Human Studies, 40(4), 519-542.

Bauman, Z. (2000). Liquid modernity. Cambridge, UK: Polity Press. 
Bayliss, P. (2010). Videogames, interfaces, and the body. The importance of embodied phenomena to the experience of videogame play. PhD thesis, RMIT University School of Media and Communication, Australia.

Beck, U. (1994). The reinvention of politics: Towards a theory of reflexive modernization. In U. Beck, A. Giddens, \& S. Lash (Eds.), Reflexive modernization: Politics, tradition and aesthetics in the modern social order (pp. 1-55). Cambridge, UK: Polity Press.

Boden, D., \& Molotch, H. (1994). The compulsion to proximity. In R. Friedland \& D. Boden (Eds.), Nowhere: Space, time and modernity (pp. 257-286). Berkeley: University of California Press.

Bourdieu, P. (1996). Physical space, social space and habitus. Oslo: Universitetet i Oslo, Institutt for sociologi og samfunnsgeografi.

Butnaru, D. (2015). Phenomenological alternatives of the lifeworld: Between multiple realities and virtual realities. SocietáMutamentoPolitica, 6(12), 67-80.

Campbell, C. (1987). The romantic ethic and the spirit of modern consumerism. Oxford, New York: Basil Blackwell.

Cass, K. (1998). The world wide web's shadow of opportunity. A Heideggerian perspective of authenticity in the information age. Information Technology \& People, 11(4), 328-337.

Chin, G. P. W.-H. (2017). Observed bodies and tool selves. Kinaesthetic empathy and the videogame avatar. Digital Creativity, 28(3), 206-223.

Couldry, N., \& Hepp, A. (2017). The mediated construction of reality. Cambridge, UK: Polity Press.

Crick, T. (2011). The game body. Toward a phenomenology of contemporary video gaming. Games and Culture, 6(3), 259-269.

Di Letizia, R. (n.y.). What is it like to be an avatar? The phenomenology of immersion in computer games. Manuscript. https://www.academia.edu/12022366/What_is_it_like_to_be_an_Avatar_The_Pheno menology_of_Immersion_in_Computer_Games.

Dubbelman, T. (2013). Narratives of being there. Computer games, presence and fictional worlds. $\mathrm{PhD}$ thesis. Utrecht: Utrecht University.

Durkheim, É. (1899/1982). Social morphology. In S. Lukes (Ed.), The rules of sociological method (pp. 241242). New York, NY: Free Press.

Durkheim, É., \& Mauss, M. (1903/1963). Primitive classification. London: Cohen and West.

Foucault, M. (1982/1984). Space, power and knowledge. In P. Rabinow (Ed.), The Foucault reader (pp. 239256). New York: Pantheon.

Friesen, N. (2014). Telepresence and tele-absence. A phenomenology of the (in)visible alien online. Phenomenology \& Practice, 8(1), 17-31.

Giddens, A. (1985). Time, space and regionalisation. In D. Gregory \& J. Urry (Eds.), Social relations and spatial structures (pp. 265-295). Houndmills: Macmillan.

Giddens, A. (1991). Consequences of modernity. Cambridge, UK: Polity Press.

Giddens, A. (1992). The transformation of intimacy. Sexuality, love and eroticism in modern societies. Stanford: Stanford University Press.

Giddens, A. (1994). Living in a post-traditional society. In U. Beck, A. Giddens, \& S. Lash (Eds.), Reflexive modernization. Politics, tradition and aesthetics in the modern social order (pp. 56-109). Cambridge, UK: Polity Press.

Guéhenno, J-M. (1993/1995). The end of the nation-state. Minneapolis, MN: University of Minnesota Press.

Günzel, S. (2019a). What do they represent? Computer games as spatial concepts. In E. Aarseth \& S. Günzel (Eds.), Ludotopia. Spaces, places and territories in computer games (pp. 13-40). Bielefeld: Transcript Verlag.

Günzel, S. (2019b). The lived space of computer games. In A. Gerber \& U. Götz (Eds.), Architectonics of game spaces. The spatial logic of the virtual and its meaning for the real (pp. 167-181). Bielefeld: Transcript.

Hardesty, R. A. (2016). Living-into, living-with: A Schutzian account of the player/character relationship. Glimpse, 17, 27-34.

Hardesty, R. A., \& Sheredos, B. (2019). Being together, worlds apart. A virtual-worldly phenomenology. Human Studies, 42(3), 343-370.

Harvey, D. (1989). The condition of postmodernity. An enquiry into the origins of cultural change. Cambridge, MA: Blackwell.

Harvey, D. (2001). Spaces of capital. Towards a critical geography. New York, NY: Routledge.

Houliez, C., \& Gamble, E. (2013). Dwelling in second life? A phenomenological evaluation of online virtual worlds. Virtual Reality, 17(3), 263-278. 
Klevjer, R. (2012). Enter the avatar. The phenomenology of prosthetic telepresence in computer games. In J. Sageng, H. Fossheim, \& L. T. Mandt (Eds.), The philosophy of computer games (pp. 17-38). Dordrecht: Springer.

Latour, B. (1991/1993). We Have Never Been Modern. Cambridge, MA: Harvard University Press.

Law, J. (2002). Objects and spaces. Theory, Culture and Society, 19(5-6), 91-105.

Lefebvre, H. (1974/1991). The production of space. Oxford: Basil Blackwell.

Longhurst, R. (2013). Using Skype to mother: Bodies, emotions, visuality, and screens. Environment and Planning D: Society and Space, 31(4), 664-679.

Löw, M. (2001/2016). The sociology of space. Materiality, social structures, and action. New York, NY: Palgrave Macmillan.

Löw, M., \& Weidenhaus, G. (2017). Borders that relate: Conceptualizing boundaries in relational space. Current Sociology, 65(4), 553-570.

Mayol, P. (1994/1998). Part I: Living. In: M. de Certeau, L. Giard, \& P. Mayol (Eds.) Practice of everyday life, volume 2: Living and cooking (pp. 5-129). Minneapolis and London: University of Minneapolis Press.

Merleau-Ponty, M. (1945/2012). Phenomenology of perception. London, NY: Routledge.

Möring, M. (2019). Distance and fear. Defining the play space. In E. Aarseth \& S. Günzel (Eds.), Ludotopia. Spaces, places and territories in computer games (pp. 231-244). Bielefeld: Transcript Verlag.

Nitsche, M. (2008). Video game spaces. Image, play, and structure in 3D game worlds. Cambridge: MIT Press.

Nitsche, M. (2019). No end of worlds. In E. Aarseth \& S. Günzel (Eds.), Ludotopia. Spaces, places and territories in computer games (pp. 201-212). Bielefeld: Transcript Verlag.

Ollinaho, O. I. (2018). Virtualization of the life-world. Human Studies, 41(2), 193-209.

Pargman, D. (2008). Do you believe in magic? Computer games in everyday life. European Journal of Cultural Studies, 11(2), 225-244.

Riva, G., Waterworth, J. A., \& Waterworth, E. L. (2004). The layers of presence: A bio-cultural approach to understanding presence in natural and mediated environments. CyberPsychology \& Behavior, 7(4), 405-419.

Schivelbusch, W. (1977/1986). The railway journey: The industrialization of time and space in the nineteenth century. Berkeley: University of California Press.

Schultze, U. (2010). Embodiment and presence in virtual worlds. Journal of Information Technology, 25(4), 434-449.

Schutz, A. (1932/1967). The phenomenology of the social world. Evanston, IL: Northwestern University Press.

Schutz, A. (1945/1962). On multiple realities. In Collected papers I. The problem of social reality (pp. 207259). The Hague, Boston, London: Martinus Nijhoff.

Schutz, A., \& Luckmann, T. (1973). Structures of the life-world. London: Heinemann.

Scriven, P. (2015). The phenomenology of the "other" in computer game worlds. Games and Culture, 13(2), 193-210.

Seiler, S. J., \& Kidwell, J. (2016). Defining the mobile-digital situation within perpetual telecopresence. An exploratory study of the impact of mobile phones on the life-world. Sociological Spectrum, 36(4), 208-235.

Shields, R. (1991). Places on the margin. alternative geographies of modernity. London, New York, NY: Taylor and Francis.

Shields, R. (2006). Virtualities. Theory, Culture \& Society, 23(2-3), 284-286.

Simmel, G. (1907/2009). Sociology: Inquiries into the construction of social forms. Leiden: Brill.

Soja, E. (1989). Postmodern geographies. London, NY: Verso.

Steets, S. (2019). Games as provinces of meaning. In A. Gerber \& U. Götz (Eds.), Archtectonics of game spaces. The spatial logic of the virtual and its meaning for the real (pp. 85-93). Bielefeld: Transcript.

Taylor, T. L. (2002). Living digitally. Embodiment in virtual worlds. In R. Schroeder (Ed.), The social life of avatars presence and interartion in shared virtual environments (pp. 40-62). London: Springer.

Vertesi, J. (2008). The London underground map and users' representations of urban space. Social Studies of Science, 38(1), 7-33.

Virilio, P. (1998/2005). The information bomb. London, New York: Verso.

Waldenfels, B. (2009). Ortsverschiebungen, Zeitverschiebungen. Frankfurt am Main: Suhrkamp.

Weber, M. (1904-1905). The protestant ethic and the spirit of capitalism. Oxford, NY: Oxford University Press. 
Zhao, S. (2004). Consociated contemporaries as an emergent realm of the lifeworld: Extending Schutz's phenomenological analysis to cyberspace. Human Studies, 27(1), 91-105.

Zhao, S. (2005). The digital self: Through the looking glass of telecopresent others. Symbolic Interaction, 28(3), 387-405.

Zhao, S. (2015). Constitution of mutual knowledge in telecopresence. Updating Schutz's phenomenological theory of the lifeworld. Journal of Creative Communications, 10(2), 105-127.

Publisher's Note Springer Nature remains neutral with regard to jurisdictional claims in published maps and institutional affiliations. 